\title{
Rectal and oral absorption of methylprednisolone acetate
}

\begin{abstract}
Rectal absorption of methylprednisolone acetate and oral absorption of methylprednisolone and methylprednisolone acetate were investigated in a single-dose 3-way crossover study of 12 normal male volunteers. The median value of bioavailability (relative to oral dose) of methylprednisolone acetate based on unchanged methylprednisolone plasma levels was $14.2 \%$ after rectal administration, suggesting that the drug exerts its therapeutic effect topically rather than systemically. In contrast, the median of total radioactivity in urine (as a percentage of rectal dose) was $34.3 \%$ (range, $4.52 \%$ to $58.8 \%$ ), suggesting partial bacterial metabolism in the rectum prior to absorption. Mean bioavailability (relative to oral administration of methylprednisolone acetate) of methylprednisolone after oral administration was $89.9 \%$, indicating somewhat better systemic availability of the ester than the alcohol. The average apparent elimination rate constant for methylprednisolone after oral administration of both ester and alcohol was $0.290 \mathrm{hr}^{-1}$, corresponding to a half-life of $2.39 \mathrm{hr}$.
\end{abstract}

\author{
Dyal C. Garg, Ph.D., John G. Wagner, Ph.D., Ermelinda Sakmar, M.A., \\ Donald J. Weidler, M.D., Ph.D., and Kenneth S. Albert, Ph.D. \\ Ann Arbor and Kalamazoo, Mich. \\ College of Pharmacy, The University of Michigan and Upjohn Center for Clinical \\ Pharmacology, The Upjohn Company
}

Methylprednisolone acetate (Depo-Medrol) is a potent glucocorticoid used intramuscularly in aqueous suspension for patients with adrenal insufficiency or dermatoses. $1{ }^{13}$ A different aqueous suspension of this steroid has also been used as a retention enema (Medrol Enpak) for the treatment of patients with ulcerative colitis. Rectal absorption of corticosteroids has not been studied extensively and it is still not known whether corticosteroid enemas are locally effective ${ }^{8,11}$ or systemically effective. ${ }^{5}$ In 1 study, the 24-hr urinary excretion of ${ }^{14} \mathrm{C}$ labeled prednisone was found to be $72 \%$ of the

Supported by The Upjohn Company, Kalamazoo, Mich.

Received for publication Feb. 3, 1979.

Accepted for publication Feb. 24, 1979.

Reprint requests to: Kenneth S. Albert, Ph.D., Medical Bioavailability Unit, The Upjohn Company, Kalamazoo, MI 49001. rectal dose. ${ }^{4}$ Spencer et al. ${ }^{13}$ studied the rectal absorption of radioactive 6- $\alpha$-methylprednisolone and reported $18 \%$ to $64 \%$ radioactive urinary excretion of the rectal dose in $48 \mathrm{hr}$. In yet another study, rectal absorption of radioactive methylprednisolone was found to be about $22 \%$ that of oral absorption. ${ }^{10}$ Data on rectal absorption of methylprednisolone acetate have not been reported to date. We report the results of a single-dose 3-treatment crossover study designed to determine bioavailability of methylprednisolone acetate after rectal administration.

\section{Materials and methods}

Protocol. Twelve normal, healthy male subjects (aged, 22 to $44 \mathrm{yr}$; body weight, 60 to 82 $\mathrm{kg}$ ) were selected for the study.

All study subjects received no steroid prep- 
Table I. Treatment schedules

\begin{tabular}{c|c|c|c|c}
\hline \multirow{2}{*}{ Group } & Subjects & \multicolumn{3}{|c}{ Time period } \\
\cline { 3 - 5 } & \multicolumn{1}{|c|}{$\begin{array}{c}\text { Phase I } \\
\text { (week 1) }\end{array}$} & $\begin{array}{c}\text { Phase II } \\
\text { (week 2) }\end{array}$ & $\begin{array}{c}\text { Phase III } \\
\text { (week 3) }\end{array}$ \\
\hline I & $2,4,9,11$ & $\mathrm{~A}$ & $\mathrm{~B}$ & $\mathrm{C}$ \\
II & $3,5,10,12$ & $\mathrm{~B}$ & $\mathrm{C}$ & $\mathrm{A}$ \\
III & $1,6,7,8$ & $\mathrm{C}$ & $\mathrm{A}$ & $\mathrm{B}$ \\
\hline
\end{tabular}

aration for a period of 60 days preceding the study. They received no barbiturates or other enzyme inducers from 30 days before the study until its completion. They received no other medication or alcoholic beverages for a period beginning 7 days before the study until its completion.

The treatments were as follows: treatment A-10 $\mathrm{ml}$ aqueous suspension of methylprednisolone, $3.60 \mathrm{mg} / \mathrm{ml}$ (equivalent to $4.0 \mathrm{mg} / \mathrm{ml}$ of methylprednisolone acetate) administered orally; treatment $\mathrm{B}-10 \mathrm{ml}$ aqueous suspension of methylprednisolone acetate, $4 \mathrm{mg} / \mathrm{ml}$ orally; treatment $\mathrm{C}$-methylprednisolone acetate suspension formulated to contain $50 \mu \mathrm{Ci}{ }^{3} \mathrm{H}$ methylprednisolone acetate (6- $\alpha$-methylprednisolone-21-acetate $1,2,4-{ }^{3} \mathrm{H}$ ); a dose of $40 \mathrm{mg}$ (specific activity, $1.25 \mu \mathrm{Ci} / \mathrm{mg}$ ) was added to $30 \mathrm{ml}$ warm water and administered as a retention enema.

The subjects fasted overnight (from 10 P.M.) until $4 \mathrm{hr}$ after administration of each treatment. The oral doses were taken in the morning (about 8 A.M.) with $180 \mathrm{ml}$ water. The treatment schedules are shown in Table I.

Sampling. Blood samples were drawn at $0 \mathrm{hr}$ and then again following treatments $\mathrm{A}, \mathrm{B}$, and $\mathrm{C}$ at $1 / 2,1,2,3,4,6,8,10,12$, and $14 \mathrm{hr}$. Samples following treatments $\mathrm{B}$ and $\mathrm{C}$ were also collected at 24 and $36 \mathrm{hr}$ after dosing. A blood sample was drawn immediately after administration of the enema in treatment $C$.

All blood specimens were drawn by $7-\mathrm{ml}$ Vacutainers of $50 \mathrm{mg}$ sodium fluoride and $5 \mathrm{mg}$ thymol [sodium fluoride was found to inhibit hydrolysis of methylprednisolone acetate to methylprednisolone (alcohol) in fresh human blood $^{2}$.

Urine and fecal collections were made during $24 \mathrm{hr}$ for 5 consecutive days following treatment
Table II. Results of HPLC assay of samples from different treatments

\begin{tabular}{c|c|c}
\hline Treatment & $\begin{array}{c}\text { Amount } \\
\text { of steroid } \\
(\mathrm{mg})\end{array}$ & $\begin{array}{c}\text { Equivalent of } \\
\text { methylprednisolone } \\
(\mathrm{mg})\end{array}$ \\
\hline $\mathrm{A}$ & 32.8 & 32.8 \\
$\mathrm{~B}$ & 36.6 & 32.9 \\
$\mathrm{C}$ & 36.8 & 33.1 \\
\hline
\end{tabular}

*Average of 3 determinations.

$\mathrm{C}$ only. Urine samples were collected in polyethylene containers. The total volume from each collection was measured and an aliquot kept at $-20^{\circ}$ for subsequent assay for total radioactivity. Fecal samples were collected in 1-gallon empty paint cans. Fecal samples were homogenized with 1 to 2 times their weight of water and an aliquot was kept for subsequent assay.

Determination of actual doses for different treatments. The contents of 1 vial from each treatment were dissolved in $500 \mathrm{ml}$ methanol. Three aliquots of each were analyzed by highpressure liquid chromatography (HPLC) for methylprednisolone (treatment A) or methylprednisolone acetate (treatments B and C). The averages of the assays are listed in Table II. For treatment $\mathrm{C}$, the radioactivity of the same bottle was also determined by scintillation counting. The $36.8 \mathrm{mg}$ methylprednisolone acetate or $33.1 \mathrm{mg}$ methylprednisolone shown in Table II were equivalent to $52 \mu \mathrm{Ci}$. After each treatment $\mathrm{C}$, the residual radioactivity in the enema bag and tubing was measured and subtracted from $52 \mu \mathrm{Ci}$ to yield the radioactive dose for each subject. The radioactive dose was then converted to milligrams of methylprednisolone by use of HPLC assay results shown in Table II.

Assay of plasma, urine, and fecal samples. Two milliliters of plasma were used for deter- 


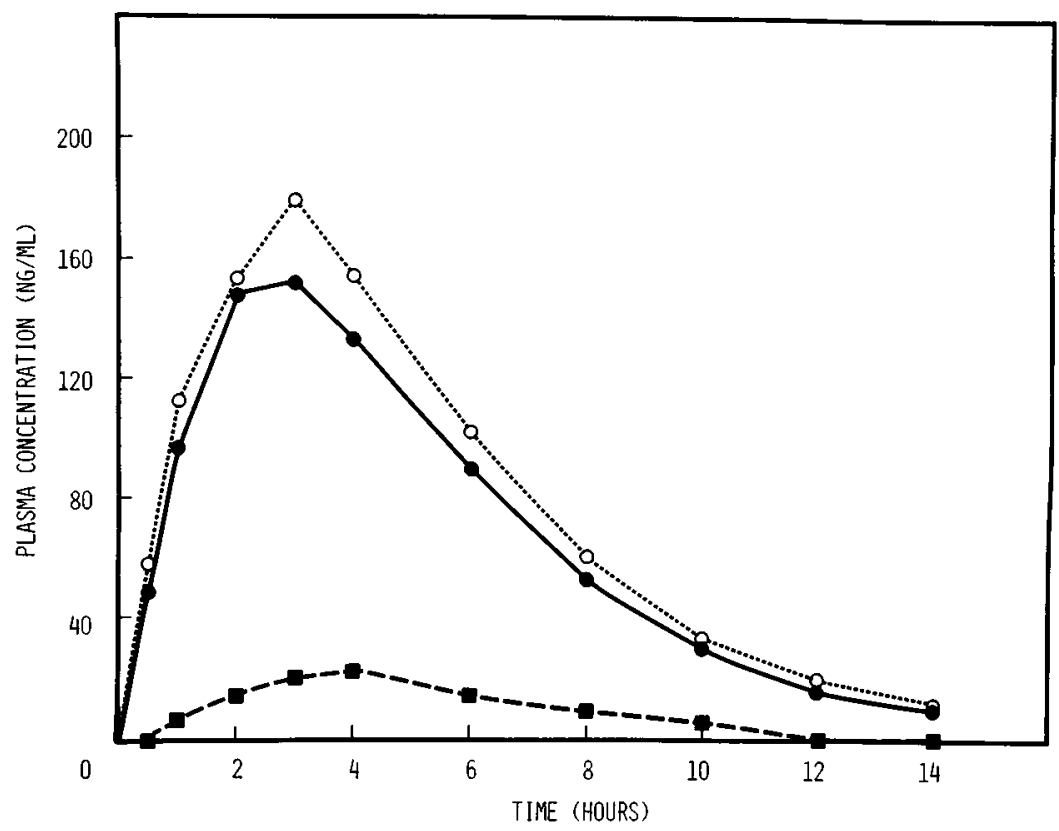

Fig. 1. Plot of average plasma concentrations of methylprednisolone against time. Treatment A, •; treatment $\mathrm{B}$, o; treatment $\mathrm{C}$, $\mathbf{a}$.

Table III. Time of first bowel movement, radioactivity in feces and urine, and the total area under the curve for methylprednisolone following rectal administration of methylprednisolone acetate (treatment $C$ )

\begin{tabular}{c|c|c|c|c}
\hline \multirow{2}{*}{ Subject } & $\begin{array}{c}\text { Time of first } \\
\text { bowel movement } \\
(\mathrm{hr})\end{array}$ & \multicolumn{2}{|c|}{$\begin{array}{c}\text { Radioactivity } \\
(\% \text { of dose })\end{array}$} & \multirow{2}{*}{$\begin{array}{c}(\text { AUC } 0-\infty)_{c} \\
{[(\mathrm{mg} / \mathrm{ml}) \times \mathrm{hr}]}\end{array}$} \\
\cline { 3 - 4 } & 10.7 & Urine & Feces & 413 \\
2 & 23.0 & 50.3 & 22.6 & 166 \\
3 & 8.25 & 58.8 & 13.5 & 234 \\
4 & 22.0 & 39.0 & 22.1 & 171 \\
5 & 1.17 & 49.6 & 10.6 & $-^{*}$ \\
6 & 36.0 & 4.52 & 69.3 & 315 \\
7 & 6.17 & 45.2 & 14.6 & 211 \\
8 & 1.17 & 45.9 & 19.6 & $-{ }^{*}$ \\
9 & 1.67 & 5.13 & 65.6 & $-*$ \\
10 & 1.33 & 7.31 & 66.7 & 283 \\
11 & 7.5 & 4.68 & 69.9 & 115 \\
12 & 2.25 & 29.6 & 33.4 & 169 \\
Median & & 13.1 & 63.5 & \\
\hline
\end{tabular}

*Concentrations in all samples were too low for detection by HPLC assay.

mination of methylprednisolone and methylprednisolone acetate by means of an HPLC method. ${ }^{2}$ The chromatographic separations were done on a $\mu$-Bondapak $\mathrm{C}_{18}$ column and the carrier solvent was methanol, water, and acetic acid in a ratio of $56: 39: 5$ by volume at a flow rate of $1.6 \mathrm{ml} / \mathrm{min}$. The quality-control samples were prepared by using plasma obtained from other volunteers. The blood was collected in Vacutainers containing sodium fluoride, and the plasma was spiked with methylprednisolone and methylprednisolone acetate to produce concentrations of 140 and $100 \mathrm{ng} / \mathrm{ml}$, respectively. An assay on at least 1 quality-control sample was run each day that unknowns were assayed.

Urine $(1$ or $1.5 \mathrm{ml})$ from each sample col- 
Table IV. Bioavailability (relative to oral dose) of methylprednisolone acetate after rectal administration

\begin{tabular}{|c|c|c|c|c|c|}
\hline Subject & $\begin{array}{l}(A U C O-x)_{B} \\
{[(n g / m l) \times h r]}\end{array}$ & $\begin{array}{c}\text { Dose } B \\
\quad(m g)\end{array}$ & $\begin{array}{c}\left(A U C 0^{-x}\right)_{C} \\
{[(n g / m l) \times h r]}\end{array}$ & $\begin{array}{c}\text { Dose C } \\
\text { (mg) }\end{array}$ & $\begin{array}{c}\text { bioavailability of } \\
C(\%)=\frac{\left(A U C 0^{-\infty}\right)_{C} / D_{C}}{\left(A U C 0^{-\infty}\right)_{B} / D_{B}} \times 100\end{array}$ \\
\hline 1 & 862 & 32.9 & 413 & 28.7 & 54.9 \\
\hline 2 & 1,373 & 32.9 & 166 & 27.8 & 14.3 \\
\hline 3 & 727 & 32.9 & 234 & 29.8 & 35.5 \\
\hline 4 & 1,241 & 32.9 & 171 & 29.4 & 15.4 \\
\hline 5 & 792 & 32.9 & _* & 29.2 & $-\dagger$ \\
\hline 6 & 1,554 & 32.9 & 315 & 29.9 & 22.3 \\
\hline 7 & 1,654 & 32.9 & 211 & 29.6 & 14.2 \\
\hline 8 & 1,096 & 32.9 & $-*$ & 26.9 & -+ \\
\hline 9 & 1,253 & 32.9 & -* $^{*}$ & 30.5 & -+ \\
\hline 10 & 1,175 & 32.9 & -* & 27.5 & $-\dagger$ \\
\hline 11 & 1,830 & 32.9 & 283 & 27.7 & 25.3 \\
\hline 12 & 990 & 32.9 & 115 & 27.2 & 14.1 \\
\hline Median & & & & & 14.2 \\
\hline
\end{tabular}

*The area in these subjects was considered to be 0 because in all samples the methylprednisolone plasma levels were too low for detection by assay.

†For calculation of the median, these bioavailabilities were considered to be equal to 0 .

lected following treatment $\mathrm{C}$ was counted in a liquid scintillation counter (Packard 3320) for total radioactivity. The counts per minute were converted to disintegrations per minute by use of a quench factor.

Fecal homogenates $(0.1$ to $1 \mathrm{gm})$ were weighed directly into combustion cones and dried overnight at room temperature. The samples were combusted using the Packard Tri Carb Sample Oxidizer Model 306. The instrument collected the water in a scintillation vial and added scintillation fluid automatically. A piece of filter paper was burned after each sample and the water was collected in the vial, used for collecting water from the sample. The recovery of radioactivity by the combustion procedure was determined by adding a known amount of radioactivity to the fecal samples, combusting the samples, and counting the collected water. The average recovery from 4 determinations was $98.3 \%$ (coefficient of variation, $7.17 \%$ ).

\section{Results}

Precision of analytical method. The precision of the HPLC method was indicated by coefficients of variation calculated from 2 types of data-those calculated from concentrations estimated by standard curve data were $4.2 \%$ for methylprednisolone and $4.6 \%$ for methylprednisolone acetate and those of concentrations es- timated by analysis of the quality-control samples were $6.5 \%$ for methylprednisolone and $7.0 \%$ for methylprednisolone acetate (qualitycontrol samples analyzed over 16 days).

HPLC analysis of plasma samples. All plasma samples collected after oral (treatment B) and rectal (treatment C) methylprednisolone acetate contained only methylprednisolone alcohol and no intact ester. Average plasma concentrations of methylprednisolone after treatments A, B, and C are plotted in Fig. 1. The concentrations of methylprednisolone at 24 and $36 \mathrm{hr}$ after treatments B and C were too low for detection by the HPLC assay method (i.e., $\leq 5$ $\mathrm{ng} / \mathrm{ml}$ ). The plasma concentrations of methylprednisolone in all samples collected from subjects who had their first bowel movements within $2 \mathrm{hr}$ of rectal administration of methylprednisolone acetate were also too low for detection by HPLC assay.

Total area (AUC $0-\infty$ ) under the methylprednisolone plasma concentration-time curve was calculated for each subject after each treatment, where feasible, by use of equations 1 to 3 :

$$
\begin{aligned}
\text { AUC } 0-\infty & =\mathrm{AUC} 0-\mathrm{T}+\hat{\mathrm{C}}_{\mathrm{T}} / \beta \\
\ln \mathrm{C} & =\ln \mathrm{B}-\beta \mathrm{t} \\
\hat{\mathrm{C}}_{\mathrm{T}} & =\mathrm{e}^{(\ln \mathrm{B}-\beta \mathrm{T})}
\end{aligned}
$$

In equations 1 to 3 , AUC 0-T is the area estimated by trapezoidal rule up to time $\mathrm{T}$; $\mathrm{T}$ is the last sampling time when the observed concen- 
Table V. Bioavailability (relative to oral administration of methylprednisolone acetate) of methylprednisolone after oral administration

\begin{tabular}{c|c|c|c}
\hline Subject & $\begin{array}{c}(A U C O-x)_{A} \\
{[(n g / m l) \times h r]}\end{array}$ & $\begin{array}{c}\left(A U C O^{-x}\right)_{B} \\
{[(n g / m l) \times h r]}\end{array}$ & $\begin{array}{c}\text { bioavailability of } \\
(A U C O)-\infty)_{A} / D_{A}\end{array} \times 100$ \\
\hline 1 & 709 & 862 & 82.5 \\
2 & 1,196 & 1,373 & 87.3 \\
3 & 746 & 727 & 103 \\
4 & 1,134 & 1,241 & 91.7 \\
5 & 836 & 792 & 106 \\
6 & 1,129 & 1,554 & 72.9 \\
7 & 1,392 & 1,654 & 84.4 \\
8 & 828 & 1,096 & 75.8 \\
9 & 962 & 1,253 & 77.0 \\
10 & 1,216 & 1,175 & 104 \\
11 & 1,250 & 1,330 & 94.3 \\
12 & 1,250 & 990 & 100 \\
Median & 1,060 & 1,208 & 89.5 \\
Mean & 1,032 & 1,171 & $89.9 \dagger$ \\
C.V. $\ddagger(\%)$ & 21.3 & 24.9 & 13.0 \\
\hline
\end{tabular}

${ }^{*} \mathrm{D}_{\mathrm{A}}$ is dose in treatment $\mathrm{A}-32.8 \mathrm{mg}$ methylprednisolone. $\mathrm{D}_{\mathrm{B}}$ is dose in treatment $\mathrm{B}-36.6 \mathrm{mg}$ methylprednisolone acetate, equivalent to $32.9 \mathrm{mg}$ methylprednisolone.

tMean ratio differs from $100 \%(t=300 ; 0.02>p>0.01$.$) .$

$\ddagger$ Coefficients of variation.

tration was higher than the sensitivity limit of the HPLC assay; $C$ is the methylprednisolone plasma concentration in the terminal log-linear phase; $\beta$ is the apparent elimination rate constant obtained by the method of least squares and equation 2 ; and $\hat{C}_{\mathbf{T}}$ is the estimated plasma concentration at time $\mathrm{T}$ obtained by use of equation 3. The areas after treatment $\mathrm{C}$ are listed in Table III, while those after treatments $A$ and $B$ are listed in Table $V$.

Bioavailability of methylprednisolone acetate after rectal administration, relative to oral administration of methylprednisolone acetate, was calculated as the dose-corrected ratio of the appropriate areas for each subject and these are listed in the last column of Table IV. The median value of $14.2 \%$ indicated low systemic availability. The dose of treatment $B\left(D_{B}\right)$ was the actual dose found by HPLC assay (Table II), while the dose of treatment $C\left(D_{C}\right)$ was calculated from the difference of the Table II value and the measured radioactivity remaining in the enema bag and tubing after drug administration to each subject (Table IV).

Bioavailability of oral methylprednisolone (alcohol) relative to oral methylprednisolone acetate was estimated from the dose-corrected areas under the plasma methylprednisolonetime curves; the areas and the individual subject bioavailabilities are listed in Table V. It is evident that the bioavailability of methylprednisolone after the acetate was slightly greater than that after the alcohol.

Radioactivity measurements. Recoveries of radioactivity (as a percentage of dose) excreted in 5 days in urine and feces are listed in Table III. Total recovery of radioactivity (sum of urine and feces) averaged $68.7 \%$ (coefficient of variation, $9.2 \%$ ). Most of the radioactivity in both urine and feces was excreted in the first 24 hr. The average of the first-day excretion in urine was $81 \%$ of that excreted in 5 days, and the average of the first-day excretion in feces was $87 \%$ of that excreted in 5 days. There was a curvilinear relationship between the recovery of radioactivity in urine in 5 days and the time of the first bowel movement; the shorter the time to the first bowel movement, the lower the excretion of radioactivity in urine (see Table III).

\section{Discussion}

The absence of methylprednisolone acetate in plasma most probably resulted from rapid hy- 
Table VI. Average kinetic parameters for methylprednisolone

\begin{tabular}{|c|c|c|}
\hline \multirow[b]{2}{*}{ Parameter } & \multicolumn{2}{|c|}{ Value calculated following } \\
\hline & Treatment $A$ & Treatment $B$ \\
\hline $\begin{array}{l}\text { Apparent elimination rate } \\
\text { constant }\left(\mathrm{hr}^{-1}\right)\end{array}$ & $0.290(9.72)^{*}$ & $0.291(12.8)^{*}$ \\
\hline $\begin{array}{l}\text { Apparent elimination } t^{1 / 2} \\
\text { (hr) }\end{array}$ & 2.39 & 2.38 \\
\hline \multicolumn{3}{|l|}{ Apparent plasma clearance } \\
\hline$l / \mathrm{hr}$ & $33.2 \quad(22.5)$ & $29.9 \quad(27.0)$ \\
\hline$l /(\mathrm{kg} \times \mathrm{hr})$ & $0.492(24.5)$ & $0.444(29.2)$ \\
\hline \multicolumn{3}{|l|}{$\mathrm{V}_{\text {darea }}$} \\
\hline$l$ & $(22.9)$ & $(26.5)$ \\
\hline$l / \mathrm{kg}$ & $(22.6)$ & $1.53(29.3)$ \\
\hline
\end{tabular}

*The numbers in parentheses are coefficients of variation $(\%)$.

drolysis of the ester during absorption or in the liver before it reached the general circulation. Preliminary work ${ }^{2}$ indicated that collection of blood in containers of sodium fluoride inhibited hydrolysis of the ester between the time blood was drawn and the time of assay.

Low-level rectal absorption of methylprednisolone acetate relative to oral absorption is indicated by the mean plasma concentrations of methylprednisolone shown in Fig. 1 and by the median relative bioavailability value of $14.2 \%$ in Table IV. It should be noted that these results were obtained with the HPLC assay procedure, which specifically measured methylprednisolone and was capable of also measuring methylprednisolone acetate if the latter had appeared in plasma. This low relative bioavailability stands in contrast with the median value of $34.3 \%$ for recovery of radioactivity in the urine (Table III). A feasible explanation is bacterial metabolism of the drug in the colon followed by rectal absorption of a metabolite or metabolites along with the original acetate or methylprednisolone, its hydrolysis product.

That bacteria and molds can oxidize and reduce steroids has been known for many years. Peterson et al. ${ }^{9}$ reported that when hydrocortisone was incubated with feces, the steroid was completely metabolized in $4 \mathrm{hr}$. Nabarro et al. ${ }^{7}$ observed an increase in the urinary excretion of 17-ketosteroids after rectal infusion of hydrocortisone. Urinary excretion of 17-ketosteroids returned to normal when bacterial activity in the lower gastrointestinal tract was reduced with neomycin before or during the hydrocortisone infusion. Similar observations were made by Wade et al. ${ }^{14}$ To test this explanation, total radioactivity was measured in plasma samples of Subjects 1 and 2. The methylprednisolone plasma concentrations estimated from total radioactivity measurements were considerably higher than those obtained by the HPLC method, indicating that total radioactivity in plasma, and most probably in urine, represented both methylprednisolone and metabolites. Unfortunately, unchanged methylprednisolone could not be measured in urine because of interferring peaks. We therefore believe that rectal absorption of methylprednisolone acetate is low, indicating a topical rather than systemic effect (median, $14.2 \%$; range, $0 \%$ to $54.9 \%$; Table IV), rather than high reflected by values for recovery of radioactivity in urine (Table III). Our results indicate one pitfall in use of total recovery of radioactivity in urine $e^{4,10,13}$ to reflect rectal absorption of any drug metabolized by bacteria in the lower gastrointestinal tract.

In our study, suspensions of methylprednisolone (alcohol) were less well absorbed than suspensions of methylprednisolone acetate when taken orally, as indicated by the mean relative bioavailability value of $89.9 \%$, which, by the $t$ test, differed from the $100 \%(\mathrm{p}<0.02)$ obtainable if the mean bioavailabilities had been equal (Table V).

Methylprednisolone kinetics. The apparent elimination rate constants from fall off of methylprednisolone plasma concentration curves with time after treatments $\mathrm{A}$ and $\mathrm{B}$ were calcu- 


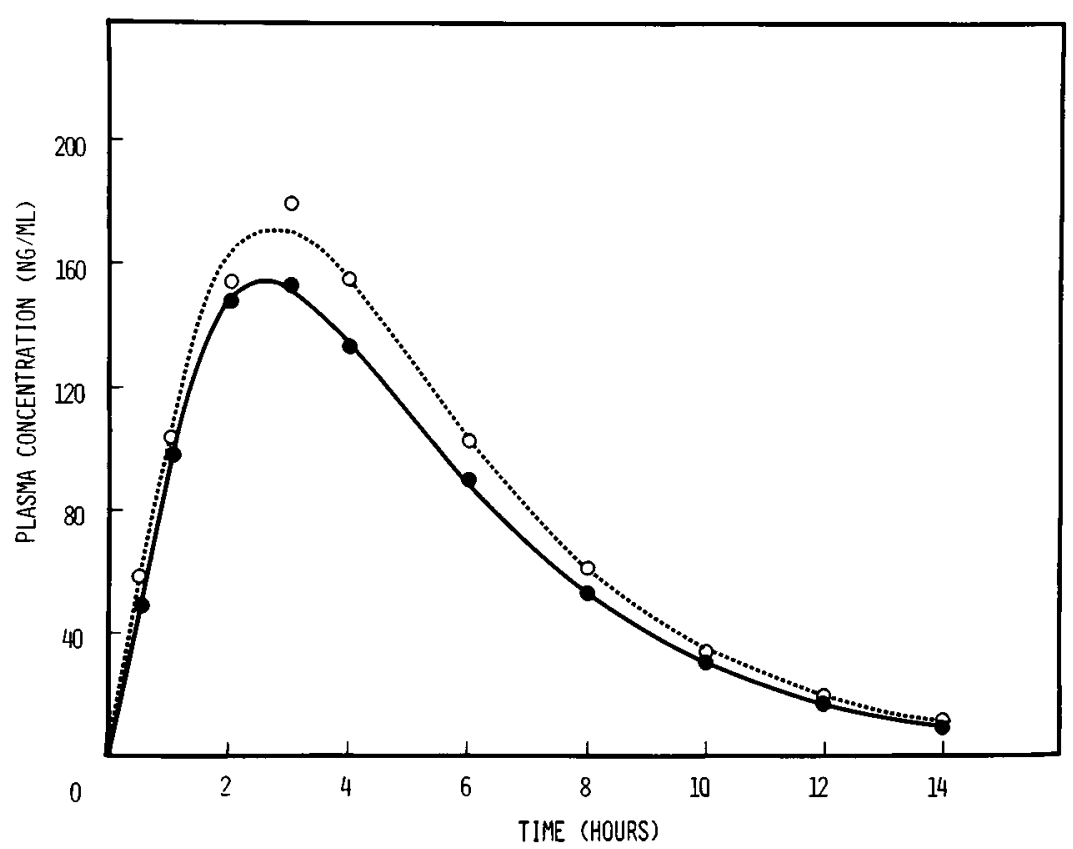

Fig. 2. Plot of average plasma concentrations of methylprednisolone against time. Treatment $A$, •; treatment $\mathrm{B}, \mathrm{o}$. The lines drawn through the points are based on a computer fitting of the plasma concentrations to the polyexponential equations given below:

$$
\begin{gathered}
\text { Treatment A: } C_{p}=86.5 \mathrm{e}^{-2.37 t}+630 \mathrm{e}^{-0.299 t}-717 \mathrm{e}^{-0.641 \mathrm{t}} \\
\text { Treatment B: } C_{p}=487 \mathrm{e}^{-1.11 \mathrm{t}}+685 \mathrm{e}^{0.2941}-117 \mathrm{e}^{-0.734 t}
\end{gathered}
$$

lated for each subject by use of equation 2 and the method of least squares.

The apparent plasma clearance, $\mathrm{Cl}_{\mathrm{p}} / \mathrm{FF},{ }^{*}$ was calculated by applying equation 4 :

$$
\mathrm{Cl}_{\mathrm{p}} / \mathrm{FF}^{*}=\frac{\text { Dose }}{\text { AUC } 0-\infty}
$$

In equation $4, \mathrm{~F}$ is the absorbed fraction of the dose $(0 \leq \mathrm{F} \leq 1)$ and $\mathrm{F}^{*}$ is the "first-pass" bioavailability factor $\left(0 \leq \mathrm{F}^{*} \leq 1\right)$. The AUC $0-\infty$ is the total area under the methylprednisolone plasma concentration-time curves calculated by equation 1 .

$\mathrm{V}_{\text {darea }}$ values (actually $\mathrm{V}_{\text {darea }} / \mathrm{FF}^{*}$ ) were estimated by means of equation 5 :

$$
\mathrm{V}_{\text {darea }}=\mathrm{Cl}_{\mathrm{p}} / \beta
$$

Table VI summarizes the kinetic parameters obtained from this study. Virtually identical kinetic parameters were obtained when the steroid ester and the alcohol were administered orally.

Fitting of oral data to polyexponential equation. The average plasma concentrationtime data obtained after oral administration of methylprednisolone and its acetate (treatments
A and B) were stripped using the program CSTRIP. ${ }^{12}$ The data were then fitted to the appropriate polyexponential equations using the program NONLIN ${ }^{6}$ and to the preliminary cstimates of the parameters obtained by use of the program CSTRIP. In Fig. 2, the solid circles and open circles are the mean plasma concentrations of methylprednisolone after treatments $\mathrm{A}$ and $\mathrm{B}$, whereas the lines drawn through the points are based on the NONLIN computer fitting of the plasma concentrations to polyexponential equations. The areas under the plasma concentration-time curves obtained by integration of the polyexponential equations ${ }^{15}$ were 1,025 and $1,172[(\mathrm{ng} / \mathrm{ml}) \times \mathrm{hr}]$ for treatments $A$ and $B$, while areas of 1,026 and 1,173 $[(\mathrm{ng} / \mathrm{ml}) \times \mathrm{hr}]$ were calculated by the trapezoidal rule.

We thank Dr. I. H. Fox of the Clinical Research Unit, University of Michigan, for letting us use his apparatus for homogenizing fecal samples and we thank Dr. B. W. Agranoff and Mr. E. B. Seguin of the Neuroscience Laboratory, University of Michigan, for allowing us to use their sample oxidizer for the analysis. 


\section{References}

1. Ferrari S, Fantoli U: Duration of blood and urinary levels of corticosteroid following intramuscular injection of methylprednisolone acetate. Clin Med 71:706-709, 1964.

2. Garg DC, Ng P, Weidler DJ, Sakmar E, Wagner JG: Preliminary in vitro and in vivo investigations on methylprednisolone and its acetate. Res Commun Chem Pathol Pharmacol 22:37-48, 1978.

3. Gibson SH: Parenteral methylprednisolone in the treatment of dermatoses. Curr Ther Res 1:122$129,1959$.

4. Halvorsen S, Myren J, Aakvaag A: On the absorption of prednisone and prednisolone disodium phosphate after rectal administration. Scan J Gastroenterol 4:581-584, 1969.

5. MacDougall I: Treatment of ulcerative colitis with rectal steroids. Lancet 1:826-827, 1963.

6. Metzler CM: A user's manual for NONLIN technical report 7292/69/7292/005. Kalamazoo, Mich., 1969, The Upjohn Company.

7. Nabarro JDN, Moxham A, Walker G, Slater JDH: Rectal hydrocortisone. Br Med J 2:272274, 1957.

8. Patterson M: Studies on the absorption of hydrocortisone from the colon of patients with idiopathic ulcerative colitis. Tex Rep Biol Med 16:508-514, 1958.
9. Peterson RE, Wyngaarden JB, Guerra SL, Brodie BB, Bunim JJ: The physiological disposition and metabolic fate of hydrocortisone in man. J Clin Invest 34:1779-1794, 1955.

10. Sanbar SS, West KM: Rectal absorption of radioactive 6-alpha-methylprednisolone in ulcerative colitis. J Med Liban 14:380-386, 1961.

11. Schwartz RD, Brodoff M, Cohn GL, Sprio HM: Rectal cortisol in the therapy of ulcerative colitis. Arch Intern Med 104:260-263, 1959.

12. Sedman AJ, Wagner JG: CSTRIP, a Fortran IV computer program for obtaining initial polyexponential parameter estimates. J Pharm Sci 65:1006-1010, 1976.

13. Spencer JA, Kirsner JB, Palmer WL: Rectal absorption of 6-alpha- $\mathrm{C}^{14}-\mathrm{H}^{3}$-prednisolone. Proc Soc Exp Biol Med 103:74-77, 1960.

14. Wade AP, Slater JDH, Kellie AE, Holliday ME: Urinary excretion of $17-$ ketosteroids following rectal infusion of cortisol. $\mathrm{J}$ Clin Endocrinol 16:444-453, 1959.

15. Wagner JG: Linear pharmacokinetic parameters from the coefficients and exponents of polyexponential equations which have been fitted to the data. Scientific commentary. J Pharmacokinet Biopharm 4:443-467, 1976. 